\title{
Performance trends in 3000 m open-water age group swimmers from 25 to 89 years competing in the FINA World Championships from 1992 to 2014
}

\author{
Knechtle, Beat ; Nikolaidis, Pantelis T ; Rosemann, Thomas ; Rüst, Christoph A
}

\begin{abstract}
We investigated trends in participation, performance and sex difference in performance in $3000 \mathrm{~m}$ freestyle in age groups swimmers (25-29 to 85-89 years) competing in the Fédération Internationale de Natation World Masters Championships between 1992 and 2014. During this period, participation increased in women and men. Women and men improved race times across years in all age groups. Women were slower in age groups 25-29 to 70-74 years. In age groups 75-79 and 85-89 years, however, race times were similar for both women and men. Sex difference in performance remained unchanged across years. In summary, performance improved across years in all age groups, men were faster than women up to the age group 70-74 years and women were not able to reduce the sex difference in performance to men across years. For athletes and coaches, an increase in participation and a continuous improvement in performance can be expected in these age group athletes.
\end{abstract}

DOI: https://doi.org/10.1080/15438627.2016.1258647

Posted at the Zurich Open Repository and Archive, University of Zurich

ZORA URL: https://doi.org/10.5167/uzh-130929

Journal Article

Accepted Version

Originally published at:

Knechtle, Beat; Nikolaidis, Pantelis T; Rosemann, Thomas; Rüst, Christoph A (2017). Performance trends in 3000 m open-water age group swimmers from 25 to 89 years competing in the FINA World Championships from 1992 to 2014. Research in Sports Medicine, 25(1):67-77.

DOI: https://doi.org/10.1080/15438627.2016.1258647 
Performance trends in 3000m open water age group swimmers from 25-89 years competing in the FINA World Championships from 1992 to 2014

Beat Knechtle ${ }^{1,2}$, Pantelis T. Nikolaidis ${ }^{3}$,Thomas Rosemann ${ }^{2}$, Christoph A. Rüst ${ }^{2}$

$1 \quad$ Gesundheitszentrum St. Gallen, St. Gallen, Switzerland

2 Institute of Primary Care, University of Zurich, Zurich, Switzerland

3 Department of Physical and Cultural Education, Hellenic Army Academy, Athens, Greece 


\begin{abstract}
We investigated trends in participation, performance and sex difference in performance in $3000 \mathrm{~m}$ freestyle in age groups swimmers (25-29 to 85-89 years) competing in the FINA World Masters Championships between 1992 and 2014. During this period, participation increased in women and men. Women and men improved race times across years in all age groups. Women were slower in age groups 25-29 to 70-74 years. In age groups 75-79 and 8589 years, however, race times were similar for both women and men. Sex difference in performance remained unchanged across years. In summary, performance improved across years in all age groups, men were faster than women up to the age group 70-74 years and women were not able to reduce the sex difference in performance to men across years. For athletes and coaches, an increase in participation and a continuous improvement in performance can be expected in these age group athletes.
\end{abstract}

Key words: master athlete, swimming, sex difference, aging 


\section{Introduction}

Open-water ultra-distance swimming has a long history with the first crossing of the 'English Channel' (Eichenberger et al., 2012). Today, open-water swimming is held in the sea (Knechtle, Rosemann, Lepers, \& Rüst 2014, Knechtle, Rosemann, \& Rüst, 2015), in large lakes (Rüst, Knechtle, Rosemann, \& Lepers, 2014) and also, since 2000 as a part of the FINA (Fédération Internationale de Natation) World Cup (Zingg, Rüst, Rosemann, Lepers, \& Knechtle, 2014a).

The performance of elite open-water swimmers competing at world class level is well investigated (Vogt, Rüst, Rosemann, Lepers, \& Knechtle, 2013, Zingg, Rüst, Rosemann, Lepers, \& Knechtle, 2014b). However, performance of age group open-water swimmers competing in different age groups at world class level is not known. For age-group pool swimmers aged 25-29 to 85-89 years and competing in FINA World Masters Championships between 1986 and 2014 participation increased from 1986 to 2014 in women and men in older age groups (i.e., 40 years and older), women and men improved across time performance in all distances, and women were not slower compared to men in age groups 8084 to 85-89 years (Knechtle, Nikolaidis, König, Rosemann, and Rüst, 2016).

In elite open-water swimmers competing in the $10 \mathrm{~km}$ FINA competitions between 2008 and 2012, swimming performances and sex differences in performance remained stable for the fastest elite open-water swimmers (Vogt, Rüst, Rosemann, Lepers, \& Knechtle, 2013). Female long-distance swimmers competing in FINA World Cup races between 2000 and 2012 improved in $10 \mathrm{~km}$ but impaired in 5 and $25 \mathrm{~km}$, whereas men only impaired in $5 \mathrm{~km}$ (Zingg, Rüst, Rosemann, Lepers, \& Knechtle, 2014b). 
The aim of the present study was to investigate trends in performance and sex difference in performance in age groups swimmers competing in the in the FINA World Masters Championships between 1992 and 2014 in 3000 m freestyle open-water swimming. 


\section{Materials and Methods}

\section{Ethics}

This study was approved by the Institutional Review Board of St. Gallen, Switzerland, with waiver of the requirement for informed consent given that the study involved the analysis of publicly available data.

\section{Data sampling and data analysis}

All data were obtained from the official and publicly accessible FINA website (www.fina.org). All female and male athletes competing in all age groups (25-29 to 85-89 years) in the FINA World Masters Championships between 1992 and 2014 in 3000 m freestyle open water were analyzed for trends in participation and performance. Following FINA, master swimmers were defined as athletes equal or older than 25 years. FINA records officially all female and male competitors in five-year age groups from 25-29 years to 105109 years. Mean race time for all athletes in all age groups for each year was calculated. The 3000m open water swimming races were held at the FINA World Masters Championships in 1992 in Indianapolis (USA), 1996 in Sheffield (Great Britain), 1998 in Casablanca (Morocco), 2000 in Munich (Germany), 2002 in Christchurch (New Zealand), 2004 in Riccione (Italy), 2006 in San Francisco (USA), 2008 in Perth (Australia), 2010 Göteborg and Borås (Sweden), 2012 in Riccione (Italy) and 2014 in Montreal (Canada).

\section{Statistical analysis}

The men-to-women ratio was calculated with all men and all women for each age group and the trend in the ratio across age groups was analyzed using single linear regression analysis. Trends in participation across years were also analysed using single linear regression analysis. To analyse changes in performance, a mixed-effects regression model with finisher as random variable to consider finishers who completed several races was used. We included sex and 
calendar year as fixed variables. Sex difference $(\%)$ was calculated using the equation ([race time in women] - [race time in men] / [race time in men] $\times 100)$. Trends in sex difference across years were analysed using single linear regression analysis. Statistical analyses were performed using IBM SPSS Statistics (Version 22, IBM SPSS, Chicago, IL, USA).

Significance was accepted at $p<0.05$ (two-sided for $t$-tests). Data in the text and tables are given as mean \pm standard deviation $(\mathrm{SD})$. 


\section{Results}

\section{Participation trends}

Between 1992 and 2014, a total of 7,597 successful finishers (2,829 women and 4,768 men) were recorded in age groups 25-29 to 85-89 years. Participation increased significantly in age groups $25-29$ to $80-84$ years in both women and men ( $p=0.01$ to $p<0.0001)$ (Figure 1$)$. No race was held in 1994. The highest numbers of swimmers were recorded in 2012. While in the first edition in 1992 the oldest swimmers were recorded for women in age group 70-74 years and for men in 75-79 years, the first swimmers in the oldest age group 85-89 year were successful in 2012 in men and in 2014 in women. In both men and women, the highest increase in the number of swimmers across years was found in age group 50-54 years. For age groups $25-29,30-34,35-39,40-44,45-49,50-54,55-59$, 60-64, 65-69, 70-74, 75-79, 80-84 and 85-89 years, the number of swimmers increased by $34,43,53,44,54,63,40,35,24,2,9$, 2 , and 2, respectively. For women, the numbers were $20,46,38,37,42,72,53,21,18,5,7$ and 0 , respectively.

\section{Performance trends}

Women and men improved race times across years in all age groups from 25-29 to 85-89 years (Figure 2 and Table 1). Women were slower in age groups 25-29 to 70-74 years. In age groups 75-79 and 85-89 years, however, race times were similar for both women and men

(Table 1). The men-to-women ratio increased across age groups $\left(\mathrm{r}^{2}=0.67, p=0.0011\right)$ from 25 29 to 85-89 years. For age groups 25-29 to 70-74 years, the men-to-women ratio increased also $\left(\mathrm{r}^{2}=0.73, p=0.0018\right)$.

\section{Sex difference in performance}

Between 1992 and 2014, the sex difference in performance remained unchanged for all age groups from 25-29 to 85-89 years (Table 2). 


\section{Discussion}

The aim of the present study was to investigate trends in performance and sex difference in performance in age groups swimmers competing in the in the FINA World Masters Championships between 1992 and 2014 in 3000 m freestyle open-water swimming. The most important findings were, (i), participation increased in all female and male age groups, (ii), performance improved in all age groups across years, (iii), men were faster than women up to age group 70-74 years and, (iv), no sex difference in performance was observed.

\section{Participation increased in women and men in all age groups}

A first important finding was that participation increased for both women and men. A very similar increase in participation has been reported for age group swimmers competing in indoor freestyle swimming at the FINA World Masters Championships held between 1986 and 2014 where participation increased in women and men in older age groups (i.e., 40 years and older) (Knechtle, Nikolaidis, König, Rosemann, and Rüst, 2016).

The most likely explanation for the increase in participation could be the increase in life expectancy in the last decades (Manton \& Vaupel 1995, Murray \& Lopez 1997, Vaupel et al. 1998, Vernay, Bonaldi, \& Grémy, 2015). Nowadays, an increasing number of elderly women and men reach higher ages with a better overall functioning (Christensen et al. 2013). The worldwide number of elderly people older than 80 years is growing steadily (http://esa.un.org/unpd/wpp). Actually, life expectancy at birth exceeds $\sim 83$ years in Japan, the current leader, and is $\sim 81$ years in several other countries (www.nia.nih.gov/research/publication/global-health-and-aging/living-longer). Nonagenarians and centenarians still have an increase in their life expectancy. For nonagenarians, for example, the number of people living past the age of 90 years has trebled to 440,000 in the last 30 years in England (www.dailymail.co.uk/news/article- 
2297069/Number-people-living-past-90-trebled-440-000-30-years.html). For centenarians, for example, the number of new centenarians in Western Europe and Japan grew at an annual rate of $7 \%$ between 1950 and 1980 by doubling every decade (www.popline.org/node/291152).

\section{Improved performance in all age groups}

A second important finding was that both women and men improved race times across years in all age groups from 25-29 to 85-89 years. This finding confirms actual results for indoor age group freestyle swimmers. At the FINA World Masters Championships between 1986 and 2014, both women and men improved their performance in freestyle swimming (Knechtle, Nikolaidis, König, Rosemann, and Rüst, 2016). For age groups 25-29 to 85-89 years, male and female performance improved across years. For age groups 25-29 to 75-79 years, men were faster than women. For age groups 80-84 and 85-89 years, women were faster than men.

A potential explanation that these elderly swimmers improved performance could be their training. Life-long exercise is associated with a favorable body composition (Hayes et al. 2013) and a higher level of physical activity is associated with a higher skeletal muscle mass (Raguso et al. 2006). For older master swimmer aged 52-82 years, it has been shown that training distance was an important factor for maintaining muscle mass and function in the aging process (Abe, Kojima, \& Stager, 2014). A study investigating French master swimmers showed positive health outcomes in terms of weight management, respiratory function, and vitality due to their race preparation (Potdevin, Vanlerberghe, Zunquin, Pezé, \& Theunynck, 2015). Positive health outcomes were higher for female master swimmers in terms of weight management, respiratory function, and vitality (Potdevin, Vanlerberghe, Zunquin, Pezé, \& Theunynck, 2015). 
The 3,000m swimming race, lasting $~ 40-140$ min depending on sex, age and year, is very demanding from a physiological perspective. According to its duration and intensity, it is considered that it taxes mainly the aerobic energy transfer system, which relies on the utilization of glycogen and fatty acids stores of human body. Considering these metabolic demands, an optimal nutrition has been demonstrated to improve endurance performance (Jeukendrup, 2011). In addition to the advancement of sport and nutrition science that improved the abovementioned practices of training and nutrition, respectively, the progress in the technology of sport equipment, such as sport clothing, might also result in the improvement of performance. For instance, a possible use of swimsuit might result in better performance (Issurin, Pushkar-Verbitsky, \& Verbitsky, 2014).

Different findings have been reported for elite open-water swimmers. In female and male elite open-water swimmers, women competing in the $5 \mathrm{~km}, 10 \mathrm{~km}$ and $25 \mathrm{~km}$ FINA World Cup races between 2000 and 2012 improved in $10 \mathrm{~km}$ but impaired in 5 and $25 \mathrm{~km}$ (Zingg, Rüst, Rosemann, Lepers, \& Knechtle, 2014b). These disparate findings might be explained by the different time frames (1992-2014 versus 2000-2012) and the different samples (elite versus master swimmers).

\section{Similar performance in women and men in age groups 75-79 and 85-89 years}

A third important finding was that men were faster than women until the age of 74 years, but not in age groups 75-79 and 85-89 years. This result is based upon very small numbers of female and male swimmers and the small number of female and male athletes up to the age of 90 years might be a very likely explanation for this finding. The men-to-women ratio increased from 25-29 to 80-89 years. In other terms, the number of women increased across age groups from 25-29 to 80-89 years relative to men. 
This finding might also be explained by anthropometric differences in elderly people since there are differences between the sexes regarding an age-related loss in skeletal muscle mass. The loss in skeletal muscle mass with advance age seems to be higher in men compared to women and to increase in men with increasing age. In people at the age of 60 years and older, the prevalence of sarcopenia was $\sim 30 \%$ in women and $\sim 45 \%$ in men (Kyle et al. 2001). In people older than 80 years, the prevalence was $\sim 31 \%$ in women and $\sim 53 \%$ in men (IannuzziSucich, Prestwood, \& Kenny, 2002). In women and men between 68 and 78 years, the rate of loss in leg muscle was significantly higher in men than in women (Zamboni et al., 2003). There are also differences between women and men for fat-free mass with increasing age. Fatfree mass remained stable up to 60 years of age in men and was lower at 75 years of age compared with the younger ages. In women, fat free mass was lower from age 60 (Larsson et al., 2015). Men older than 70 years lose significantly more fat-free mass than women (Fantin et al., 2007). Fat-free mass index decreases with age in both women and men but remains constant among the women with only a $1 \%$ decrease up to age 84 years (Seino et al., 2015).

The findings for these $3000 \mathrm{~m}$ freestyle swimmers differ from recent findings of Senefeld et al. (2015) investigating finishing times of the top ten men and women world record performances (1986-2011) between 25 and 89 years of age for $50 \mathrm{~m}$ to $1500 \mathrm{~m}$ freestyle. In their study, men were faster than women in freestyle swimming across all age groups, world record places and distances (Senefeld et al., 2015). The most likely explanation for these disparate findings are that Senefeld et al. (2015) considered top ten women and men world record performances until the age of 89 years while we considered all finishers at the FINA World Masters Championships until the age of 99 years and without selection of the top athletes. Furthermore, Senefeld et al. (2015) considered freestyle pool swimmers up to a distance of $1500 \mathrm{~m}$ while we analyzed open-water swimmers competing in $3000 \mathrm{~m}$. 


\section{No change in sex difference in performance across years}

A third important finding was that women were not able to reduce the gap in performance to men across years. Our findings differ from the findings of Senefeld et al. (2015). In their study, the sex difference in freestyle swimming speed increased with advanced age from $8.5 \pm 2.9 \%$ for the $25-29$-year olds to $20.3 \pm 3.5 \%$ for the $85-89$-year-olds (Senefeld et al. 2015). The average sex difference in freestyle swimming speed increased linearly across age groups until the age $\sim 60$ years, where the sex difference increased more rapidly between age groups (Senefeld et al., 2015). The most likely explanation is that we considered all successful finishers in the FINA World Masters Championships without a selection of the ten fastest whereas Senefeld et al. (2015) considered the world record performances of the ten fastest.

The results from these age group open-water swimmers also differ from actual reports for age group freestyle swimmers competing in indoor races from 50m to 800m (Knechtle, Nikolaidis, König, Rosemann, and Rüst, 2016). In 50m, 100m and 200m, women reduced the sex difference in performance in age groups 30-34 to 75-79 years. In 400m, women reduced the gap to men in age groups 40-44, 45-49 and 55-59 years. In 800m, the sex difference became reduced in age groups 55-59 and 70-74 years. A potential explanation could be the shorter time frame (1992-2014 for the present swimmers compared to 1986-2014 for the pool swimmers). Furthermore, the smaller number in swimmers in the present sample $(7,597$ swimmers) compared to the 65,584 swimmers for the five distances from $50 \mathrm{~m}$ to $800 \mathrm{~m}$ in the pool swimmers.

\section{Limitations}

A limitation of this study is that anthropometric characteristics and training of these athletes are not considered (VanHeest, Mahoney, \& Herr, 2004). It has been reported for longdistance open-water swimmers that body height, Body Mass Index, length of arm, and 
swimming speed during training were related to race time in men and swimming speed during training in women (Knechtle, Baumann, Knechtle, \& Rosemann, 2010). A further limitation is that fluid intake during the race was not measured. Water ingestion (i.e. planned fluid intake and/or swallowing water) during open-water swimming might lead to exerciseassociated hyponatremia (Wagner, Knechtle, Knechtle, Rüst, \& Rosemann, 2012) which might have an influence on female performance (Weitkunat, Knechtle, Knechtle, Rüst, \& Rosemann, 2012).

\section{Practical implications}

For athletes and coaches, the number of age group swimmers increased across years where the oldest swimmers (85-89 years) competed for the first time in 2012 in men and 2014 in women. We may expect that swimmers older than 90 years will soon be able to compete in this distance. Furthermore, we expect that these age group swimmers will reduce their performance continuously in the future. Coaches of elderly swimmers will need to prepare specific programs for nutrition and training.

\section{Conclusions}

In age groups swimmers (25-29 to 85-89 years) competing in $3000 \mathrm{~m}$ freestyle open-water swimming in the FINA World Masters Championships between 1992 and 2014, participation increased for women and men in all age groups, performance improved in all age groups across years, men were faster than women up to age group 70-74 years and, women were not able to reduce the sex difference to men. Future studies might investigate anthropometric characteristics of female and male age group swimmers to explain the finding that men were not faster compared to women in age groups swimmers from 75 to 89 years. We may expect in the near future a future increase in participation and a continuous improvement in performance in these age group athletes. 


\section{References}

Abe, T., Kojima, K., \& Stager, J.M. (2014). Skeletal muscle mass and muscular function in master swimmers is related to training distance. Rejuvenation Research, 17, 415-21.

Christensen, K., Thinggaard, M., Oksuzyan, A., Steenstrup, T., Andersen-Ranberg, K., Jeune, B., McGue, M. \& Vaupel, J.W (2013). Physical and cognitive functioning of people older than 90 years: a comparison of two Danish cohorts born 10 years apart. Lancet 382(9903), 1507-1513.

Eichenberger, E., Knechtle, B., Knechtle, P., Rüst, C.A., Rosemann, T., \& Lepers, R. (2012). Best performances by men and women open-water swimmers during the 'English Channel Swim' from 1900 to 2010. Journal of Sports Sciences, 30, 1295-1301.

Fantin, F., Di Francesco ,V., Fontana, G., Zivelonghi, A., Bissoli, L., Zoico, E., Rossi, A., Micciolo, R., Bosello, O., \& Zamboni, M. (2007). Longitudinal body composition changes in old men and women: interrelationships with worsening disability. The Journals of Gerontology Series A: Biological Sciences and Medical Science, 62, 1375-1381.

Hayes, L.D., Grace, F.M., Sculthorpe, N., Herbert, P., Kilduff, L.P., \& Baker, J.S. (2013). Does chronic exercise attenuate age-related physiological decline in males? Research in Sports Medicine, 21, 343-354.

Iannuzzi-Sucich, M., Prestwood, K.M., \& Kenny, A.M. (2002). Prevalence of sarcopenia and predictors of skeletal muscle mass in healthy, older men and women. The Journals of Gerontology Series A: Biological Sciences and Medical Sciences, 57, M772-777.

Issurin, V., Pushkar-Verbitsky, V., \& Verbitsky, O. (2014). Effect of high-tech swimsuits on the swimming performance in top-level swimmers. Journal of Sports Medicine and Physical Fitness, 54, 383-388.

Jeukendrup, A.E. (2011). Nutrition for endurance sports: Marathon, triathlon, and road cycling. Journal of Sports Sciences, 29, S91-99.

Knechtle, B., Baumann, B., Knechtle, P., \& Rosemann, T. (2010) Speed during training and anthropometric measures in relation to race performance by male and female open-water ultra-endurance swimmers. Perceptual and Motor Skills, 111, 463-74.

Knechtle, B., Rosemann, T., Lepers, R., \& Rüst, C.A. (2014). Women outperform men in ultradistance swimming: the Manhattan Island Marathon Swim from 1983 to 2013. International Journal of Sports Physiology and Performance, 9, 913-924.

Knechtle, B., Rosemann, T., \& Rüst, C.A. (2015). Women cross the 'Catalina Channel' faster than men. Springerplus, 4, 332.

Knechtle, B., Nikolaidis, P.T., König, S., Rosemann, T., Rüst, C.A. (2016). Performance trends in master freestyle swimmers aged 25-89 years at the FINA World Championships from 1986 to 2014. Age (Dordr) 38, 18. 
Kyle, U.G., Genton, L., Hans, D., Karsegard, V.L., Michel, J.P., Slosman, D.O., \& Pichard, C. (2001). Total body mass, fat mass, fat-free mass, and skeletal muscle in older people: cross-sectional differences in 60-year-old persons. Journal of the American Geriatrics Society, 49, 1633-1640.

Larsson, I., Lissner, L., Samuelson, G., Fors, H., Lantz, H., Näslund, I., Carlsson, L.M., Sjöström, L., \& Bosaeus, I. (2015). Body composition through adult life: Swedish reference data on body composition. European Journal of Clinical Nutrition, 69, 837-842.

Manton, K.G. \& Vaupel, J.W (1995). Survival after the age of 80 in the United States, Sweden, France, England, and Japan. The New England Journal of Medicine, 333, 12321235 .

Murray, C.J. \& Lopez, A.D (1997). Alternative projections of mortality and disability by cause 1990-2020: Global Burden of Disease Study. Lancet, 349(9064), 1498-1504.

Potdevin, F., Vanlerberghe, G., Zunquin, G., Pezé, T., \& Theunynck, D. (2015). Evaluation of global health in master swimmers involved in French National Championships. Sports Medicine-Open, 1, 12.

Raguso, C.A., Kyle, U., Kossovsky, M.P., Roynette, C., Paoloni-Giacobino, A., Hans, D., Genton, L., \& Pichard, C. (2006). A 3-year longitudinal study on body composition changes in the elderly: role of physical exercise. Clinical Nutrition, 25, 573-580.

Rüst, C.A., Knechtle, B., Rosemann, T., \& Lepers, R. (2014). Women reduced the sex difference in open-water ultra-distance swimming La Traversée Internationale du Lac St-Jean, 1955-2012. Applied Physiology Nutrition and Metabolism, 39, 270-273.

Seino, S., Shinkai, S., Iijima, K., Obuchi, S., Fujiwara, Y., Yoshida, H., Kawai, H., Nishi, M., Murayama, H., Taniguchi, Y., Amano, H., \& Takahashi, R. (2015). Reference values and age differences in body composition of community-dwelling older Japanese men and women: A pooled analysis of four cohort studies. PLoS One, 10, e0131975.

Senefeld, J., Joyner, M.J., Stevens, A., \& Hunter, S.K. (2015). Sex differences in elite swimming with advanced age are less than marathon running. Scandinavian Journal of Medicine and Science in Sports, 2015 Feb 4. doi: 10.1111/sms.12412. [Epub ahead of print]

Vaupel, J.W., Carey, J.R., Christensen, K., Johnson, T.E., Yashin, A.I., Holm, N.V., Iachine, I.A., Kannisto, V., Khazaeli, A.A., Liedo, P., Longo, V.D., Zeng, Y., Manton, K.G. \& Curtsinger, J.W (1998). Biodemographic trajectories of longevity. Science 280(5365), 855860.

VanHeest, J.L., Mahoney, C.E., \& Herr, L. (20014). Characteristics of elite open-water swimmers. Journal of Strength and Conditioning Research, 18, 302-305.

Vernay, M., Bonaldi, C. \& Grémy, I (2015). Chronic diseases: recent trends, challenges and prospects for change. Sante Publique, 27, S189-S197.

Vogt, P., Rüst, C.A., Rosemann, T., Lepers, R., \& Knechtle, B. (2013). Analysis of 10 km swimming performance of elite male and female open-water swimmers. Springerplus, 2, 603. 
Wagner, S., Knechtle, B., Knechtle, P., Rüst, C.A., and Rosemann, T. (2012). Higher prevalence of exercise-associated hyponatremia in female than in male open-water ultraendurance swimmers: the 'Marathon-Swim' in Lake Zurich. European Journal of Applied Physiology, 112, 1095-1106.

Weitkunat, T., Knechtle, B., Knechtle, P., Rüst, C.A., and Rosemann, T. (2012). Body composition and hydration status changes in male and female open-water swimmers during an ultra-endurance event. Journal of Sports Sciences, 30, 1003-1013.

Zamboni, M., Zoico, E., Scartezzini, T., Mazzali, G., Tosoni, P., Zivelonghi, A., Gallagher, D., De Pergola, G., Di Francesco, V., \& Bosello, O. (2003). Body composition changes in stable-weight elderly subjects: the effect of sex. Aging Clinical and Experimental Research, $15,321-327$.

Zingg, M.A., Rüst, C.A., Rosemann, T., Lepers, R., \& Knechtle, B. (2014a). Analysis of sex differences in open-water ultra-distance swimming performances in the FINA World Cup races in $5 \mathrm{~km}, 10 \mathrm{~km}$ and $25 \mathrm{~km}$ from 2000 to 2012. BMC Sports Science, Medicine and Rehabilitation, 6, 7.

Zingg, M.A., Rüst, C.A., Rosemann, T., Lepers, R., \& Knechtle, B. (2014b). Analysis of swimming performance in FINA World Cup long-distance open water races. Extreme Physiology \& Medicine, 3, 2. 


\section{Figure captions}

Figure 1 Participation in age groups across years in women (upper panel) and men (lower panel)

Figure 2 Race time in age groups across years in women (upper panel) and men (lower panel) 


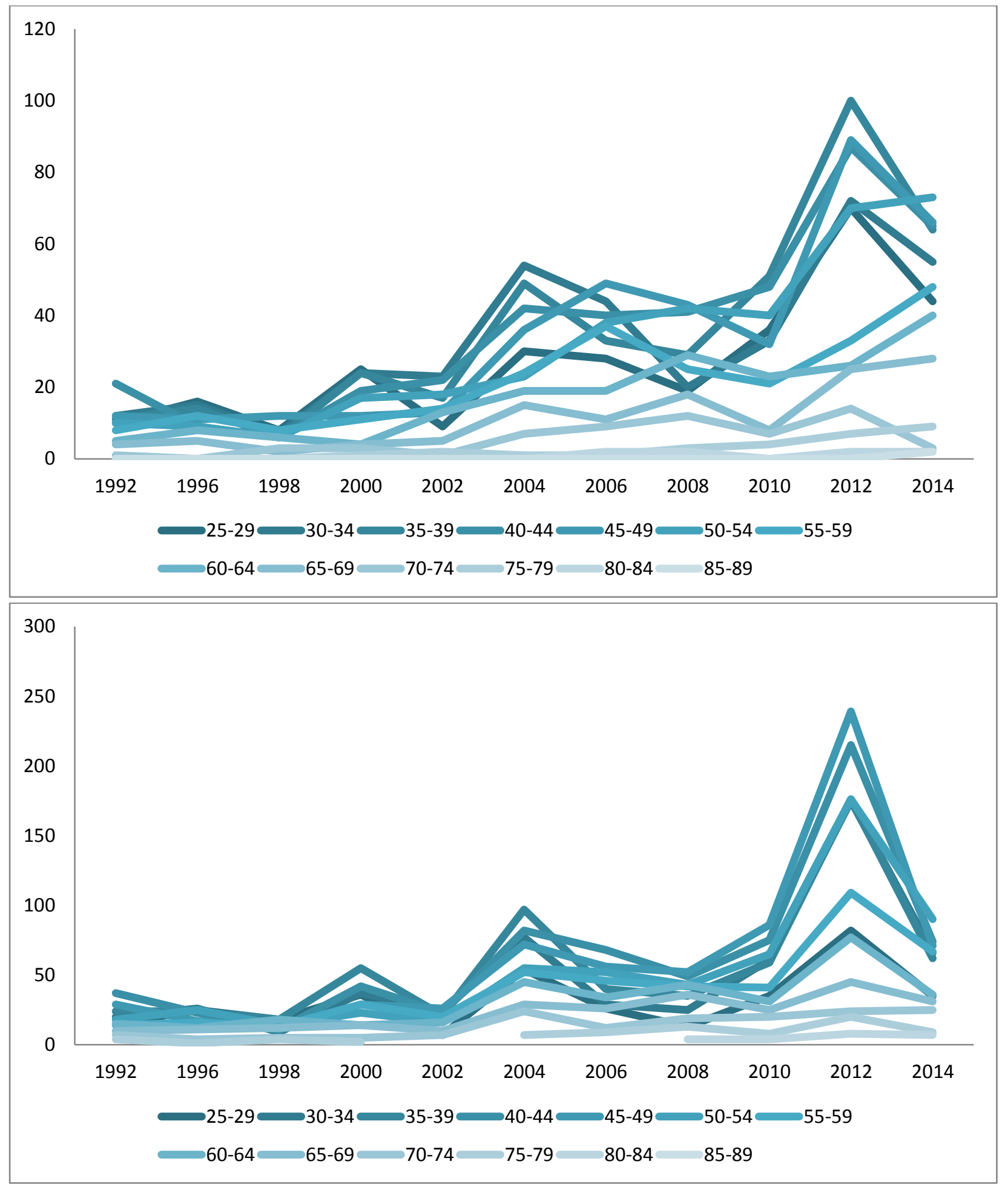

Figure 1 

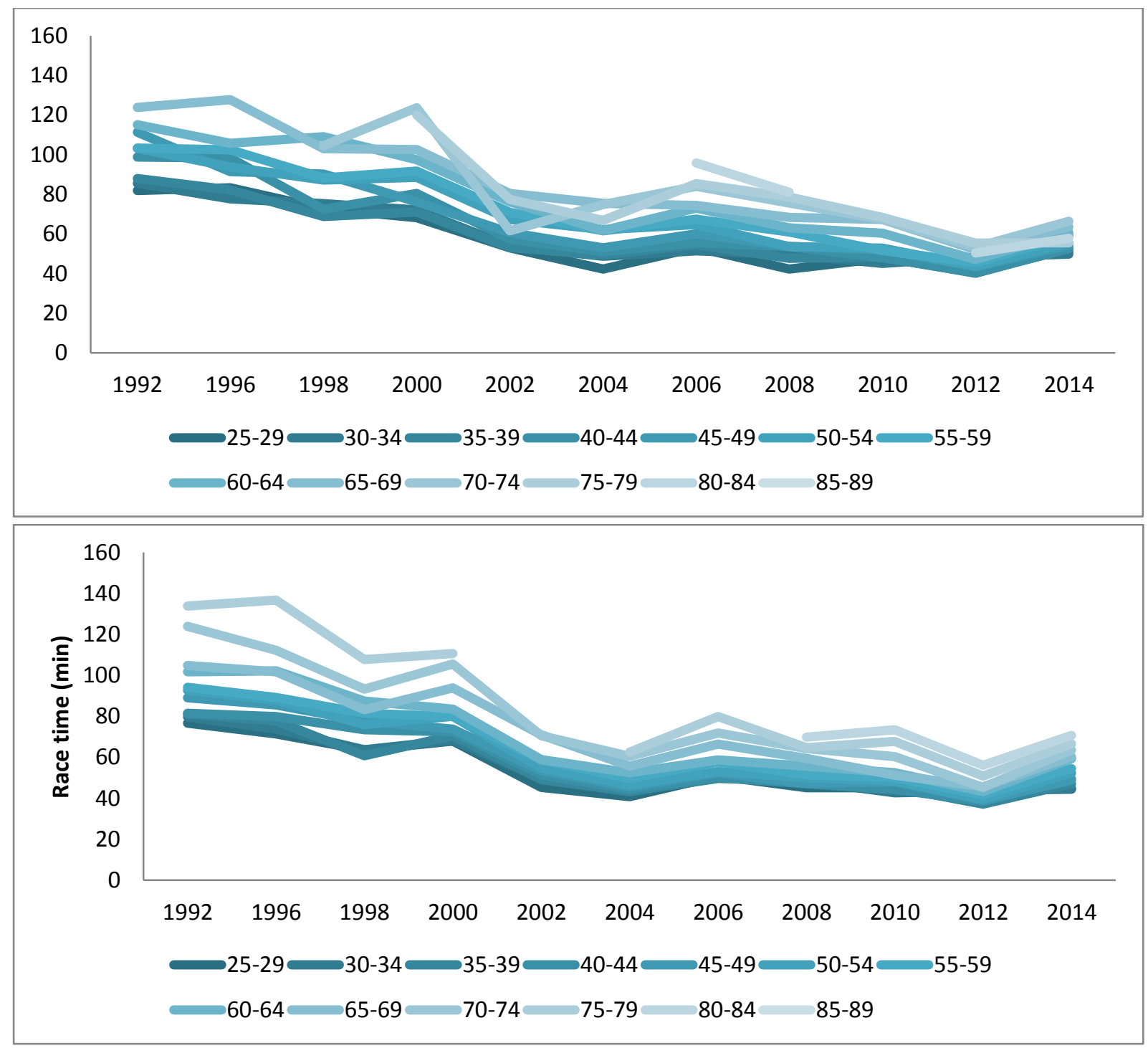

Figure 2 


\begin{tabular}{|c|c|c|c|c|c|c|}
\hline Age group & Parameter & Estimate & SE & df & $\mathbf{t}$ & $p$ \\
\hline \multirow{2}{*}{$25-29$} & Constant term & 3070.43 & 46.33 & 582.63 & 66.26 & $<0.0001$ \\
\hline & [sex=women] & 157.02 & 68.35 & 583.45 & 2.29 & 0.022 \\
\hline \multirow{2}{*}{$30-34$} & Constant term & 2966.48 & 36.27 & 835.87 & 81.78 & $<0.0001$ \\
\hline & [sex=women $]$ & 270.61 & 57.75 & 834.20 & 4.68 & $<0.0001$ \\
\hline \multirow{2}{*}{$35-39$} & Constant term & 2926.77 & 36.15 & 933.39 & 80.95 & $<0.0001$ \\
\hline & [sex=women] & 199.98 & 58.19 & 916.16 & 3.43 & 0.001 \\
\hline \multirow{2}{*}{$40-45$} & Constant term & 2971.62 & 39.36 & 988.52 & 75.48 & $<0.0001$ \\
\hline & [sex=women] & 346.10 & 65.49 & 983.87 & 5.28 & $<0.0001$ \\
\hline \multirow{2}{*}{$45-49$} & Constant term & 2972.48 & 40.56 & 960.73 & 73.27 & $<0.0001$ \\
\hline & [sex=women] & 461.44 & 68.54 & 955.22 & 6.73 & $<0.0001$ \\
\hline \multirow{2}{*}{$50-54$} & Constant term & 3114.94 & 44.57 & 834.66 & 69.88 & $<0.0001$ \\
\hline & [sex=women] & 447.74 & 72.75 & 834.64 & 6.15 & $<0.0001$ \\
\hline \multirow{2}{*}{$55-59$} & Constant term & 3334.12 & 53.79 & 606.51 & 61.97 & $<0.0001$ \\
\hline & [sex=women] & 598.15 & 90.80 & 607.56 & 6.58 & $<0.0001$ \\
\hline \multirow{2}{*}{$60-64$} & Constant term & 3598.98 & 69.37 & 463.10 & 51.88 & $<0.0001$ \\
\hline & [sex=women] & 485.84 & 116.86 & 461.31 & 4.15 & $<0.0001$ \\
\hline \multirow{2}{*}{$65-69$} & Constant term & 3853.93 & 86.06 & 307.95 & 44.77 & $<0.0001$ \\
\hline & [sex=women] & 496.11 & 148.65 & 308.53 & 3.33 & 0.001 \\
\hline \multirow{2}{*}{$70-74$} & Constant term & 4102.32 & 117.65 & 172.58 & 34.86 & $<0.0001$ \\
\hline & [sex=women] & 470.41 & 224.91 & 168.68 & 2.09 & 0.038 \\
\hline \multirow{2}{*}{$75-79$} & Constant term & 4259.43 & 174.99 & 89.27 & 24.34 & $<0.0001$ \\
\hline & [sex=women] & -235.93 & 338.94 & 89.34 & -0.69 & 0.488 \\
\hline \multirow{2}{*}{$80-84$} & Constant term & 4199.04 & 219.34 & 29.17 & 19.14 & $<0.0001$ \\
\hline & [sex=women $]$ & 248.17 & 455.26 & 29.55 & 0.54 & 0.590 \\
\hline \multirow{2}{*}{$85-89$} & Constant term & 4124.56 & 482.18 & 5 & 8.55 & $<0.0001$ \\
\hline & [sex=women] & -42.66 & 762.40 & 5 & -0.05 & 0.958 \\
\hline
\end{tabular}

Table 1 Results of the mixed-effects regression analysis 


\begin{tabular}{cccccccccccccc}
\hline Age group & $\mathbf{1 9 9 2}$ & $\mathbf{1 9 9 6}$ & $\mathbf{1 9 9 8}$ & $\mathbf{2 0 0 0}$ & $\mathbf{2 0 0 2}$ & $\mathbf{2 0 0 4}$ & $\mathbf{2 0 0 6}$ & $\mathbf{2 0 0 8}$ & $\mathbf{2 0 1 0}$ & $\mathbf{2 0 1 2}$ & $\mathbf{2 0 1 4}$ & $\mathbf{r}^{2}$ & $\boldsymbol{p}$ \\
\hline $25-29$ & 6.9 & 16.9 & 14.7 & 0.6 & 17.2 & 4.1 & 4.6 & 6.1 & 6.1 & 9.6 & 15.4 & 0.00 & 0.867 \\
$30-34$ & 7.4 & 5.4 & 18.4 & 5.5 & 8.4 & 13.6 & 0.1 & 2.8 & 6.0 & 11.3 & 11.2 & 0.00 & 0.897 \\
$35-39$ & 8.61 & 5.9 & 13.3 & 0.9 & 8.3 & 14.3 & 9.7 & 0.9 & 7.1 & 8.7 & 12.4 & 0.01 & 0.816 \\
$40-44$ & 21.3 & 23.2 & 1.2 & 11.3 & 11.8 & 15.4 & 10.8 & 14.0 & 8.6 & 5.4 & 6.7 & 0.31 & 0.073 \\
$45-49$ & 25.0 & 7.0 & 16.4 & 3.6 & 13.8 & 16.5 & 14.6 & 14.2 & 8.1 & 11.4 & 11.2 & 0.11 & 0.313 \\
$50-54$ & 11.2 & 7.0 & 14.9 & 10.6 & 23.4 & 34.0 & 22.3 & 7.5 & 9.6 & 10.8 & 6.4 & 0.01 & 0.779 \\
$55-59$ & 9.7 & 14.9 & 8.5 & 14.8 & 21.2 & 24.2 & 16.8 & 18.9 & 3.2 & 9.7 & 8.7 & 0.02 & 0.650 \\
$60-64$ & 13.1 & 3.5 & 24.9 & 16.8 & 29.6 & 17.9 & 24.5 & 13.3 & 15.1 & 9.1 & 2.6 & 0.05 & 0.491 \\
$65-69$ & 18.2 & 25.7 & 23.9 & 9.2 & 13.3 & 35.7 & 11.9 & 15.1 & 31.3 & 14.3 & 5.7 & 0.05 & 0.496 \\
$70-74$ & 20.1 & & 12.2 & 17.3 & 12.5 & 24.0 & 17.1 & 17.7 & 11.6 & 17.9 & 4.4 & 0.18 & 0.227 \\
$75-79$ & & & & 8.5 & & 7.0 & 32.0 & 21.4 & 1.0 & 9.1 & 16.3 & 0.00 & 0.979 \\
$80-84$ & & & & & & & & 16.4 & & 10.0 & 18.0 & 0.00 & 0.999 \\
\hline
\end{tabular}

Table 2 Sex difference (\%) in age groups and the analysis of the change across years 